\title{
VIABILIDADE ECONÔMICA DA UTILIZAÇÃO DO BIOGÁS PRODUZIDO EM GRANJA SUÍNÍCOLA PARA GERAÇÃ̃O DE ENERGIA ELÉTRICA
}

\author{
RICARDO G. CERVI' ${ }^{1}$, MAURA S. T. ESPERANCINI' ${ }^{2}$ OSMAR DE C. BUENO ${ }^{3}$
}

RESUMO: A produção de biogás por meio de biodigestão anaeróbia representa um avanço para equacionar o problema dos dejetos produzidos pela suinocultura e disponibilidade de energia no meio rural. Este trabalho teve como objetivo estimar a viabilidade econômica de um sistema biointegrado para geração de eletricidade a partir do aproveitamento de dejetos de suínos. Os dados para este estudo foram coletados em uma agroindústria, onde são realizadas diversas atividades agrícolas; entretanto, a suinocultura foi selecionada para o processo de análise de biodigestão anaeróbia, pelo fato de gerar uma grande quantidade de dejetos, com dificuldade de disposição no meio ambiente, configurando um estudo de caso. O biodigestor analisado é um modelo tubular contínuo, com calha de água em alvenaria e com uma manta plástica como gasômetro, onde são depositados diariamente os dejetos de 2.300 suínos em fase de terminação. $O$ investimento inicial para implantação foi estimado em $\mathrm{R} \$ 51.537,17$, e os custos anuais do sistema foram de $\mathrm{R}$ \$ 5.708,20 com manutenção, $\mathrm{R}$ \$ 4.390,40 com depreciação e R \$ 1.366,77 com juros. Concluiu-se que o sistema de produção de biogás é viável do ponto de vista econômico, se o consumo de energia elétrica for de $35 \mathrm{kWh}$ por dia, em média, onde o valor presente líquido (VLP) é de $\mathrm{R} \$ 9.494,90$, e a taxa interna de retorno (TIR) é de $9,34 \%$ ao ano.

PALAVRAS-CHAVE: biogás, energia elétrica, viabilidade econômica.

\section{ECONOMIC VIABILITY FOR ELECTRICAL POWER GENERATION USING BIOGAS PRODUCED IN SWINE GRANGE}

\begin{abstract}
Biogas production through anaerobic biodigestion represents an important breakthrough for the problem of swine waste and energy availability for rural areas. This work aimed to develop a study to estimate the economic viability of a biointegrated system installation and operation to produce electricity from swine wastes. Data for the study were collected in an agroindustry where there are plenty of agricultural activities; however the swine production activity was selected for the anaerobic digestion process because it generates a large amount of waste, with a limited provision in the environment, which characterizes a case study. The analyzed biodigester is a continuous tubular model with brick concrete duct and plastic covering with a gasometer, and where the waste of 2,300 fattening pigs are deposited daily. The initial investment estimate for the installation was $\mathrm{R} \$ 51,537.17$. The system annual costs were $\mathrm{R} \$ 5.708,20$, for maintenance, $\mathrm{R} \$$ 4,390.40 for depreciation and $\mathrm{R} \$ 1,366.77$ for interests. It was concluded that the biointegrated system would achieve favorable economic results if the energy consumption were to $35 \mathrm{~kW}$ per hour a day, in average, where the net present value (NPV) is $\mathrm{R} \$ 9,494.90$ and the internal rate of return (IRR) is $9,34 \%$ per year.
\end{abstract}

KEYWORDS: biogas, electrical power, economic viability.

\footnotetext{
${ }^{1}$ Administrador, Prof. Mestre, Faculdade de Ciências Agrárias do Vale do Ribeira, Câmpus Experimental de Registro, UNESP, Registro - SP, Fone: (0XX13) 3822.2230, rghantous@ registro.unesp.br.

${ }^{2}$ Eng ${ }^{\mathrm{a}}$ Agrônoma, Profa. Doutora, Departamento de Gestão e Tecnologia Agroindustrial, UNESP, Botucatu - SP, Fone: (0XX14) 3811.7164,maura@fca.unesp.br.

${ }^{3}$ Eng ${ }^{\mathrm{o}}$ Agrônomo, Prof. Doutor, Departamento de Gestão e Tecnologia Agroindustrial, UNESP, Botucatu - SP, Fone: (0XX14) 3811.7164,osmar@fca.unesp.br. 


\section{INTRODUÇÃO}

O crescente aumento da atividade suinícola no País e o incremento tecnológico nos sistemas de produção resulta num aumento na geração de dejetos, ocasionando problemas de ordem sanitária com perigo à saúde pela grande quantidade de organismos patogênicos presentes nesses resíduos. Quando bem conduzido, o manejo permite o aproveitamento integral dos dejetos (GASPAR, 2003).

No meio rural, os sistemas biointegrados ${ }^{1}$, especificamente com aproveitamento de biomassa para fins energéticos, podem ser um meio facilitador para atingir a sustentabilidade da produção em função da disponibilidade de biomassa nas propriedades agrícolas, por apresentar baixo custo de oportunidade dos resíduos da produção, grande potencial de geração de energia, diminuição no potencial poluidor dos resíduos, redução na pressão sobre os recursos naturais e economia de recursos energéticos (ANGONESE et al., 2006).

Desse modo, o tratamento desses efluentes por meio da biodigestão anaeróbia permite a obtenção do biogás e do biofertilizante, cujas disponibilidades contribuem para uma rápida amortização dos custos da tecnologia instalada (PECORA, 2006).

Para a criação de sistemas de biodigestores, faz-se necessário analisar a execução do projeto, para permitir a construção de instalações mais econômicas e a recuperação dos investimentos de forma mais rápida (MIRANDA, 1991).

A possibilidade de criação de fontes de suprimento descentralizadas e em pequena escala é fundamental para o desenvolvimento sustentável. Unidades que utilizam fontes renováveis e não demandam alta tecnologia para instalação ou mão de obra especializada para sua execução, são soluções principalmente para produtores rurais que podem diminuir sua dependência de energia das concessionárias de energia elétrica (COLDEBELLA, 2006).

A composição do biogás pode variar de acordo com o tipo e a quantidade de biomassa empregada, fatores climáticos, dimensões do biodigestor, entre outros. Quando as condições ambientais para o processamento de dejetos pelos microrganismos são atendidas, o biogás obtido deve ser composto de uma mistura de gases, com cerca de 60 ou $65 \%$ do volume total consistindo em metano, enquanto os 35 a 40\% restantes consistem, principalmente, de gás carbônico e quantidades menores de outros gases (SEIXAS et al., 1980).

Os dados na Tabela 1 mostram as diferentes produções de biogás de acordo com a biomassa utilizada. Nota-se que a biomassa com melhor rendimento de biogás por tonelada é oriunda de dejetos de suínos, com cerca de $560 \mathrm{~m}^{3}$ de biogás por tonelada.

TABELA 1. Estimativa de produção de biogás por quantidade de biomassa. Estimative of biogas production per amount of biomass.

\begin{tabular}{cc}
\hline Biomassa Utilizada (dejetos) & $\begin{array}{c}\text { Produção de Biogás } \\
\text { (a partir de material seco em } \text { m }^{3} \text { por tonelada) }\end{array}$ \\
\hline Bovinos & 270 \\
\hline Suínos & 560 \\
\hline Equinos & 260 \\
\hline Ovinos & 250 \\
\hline Aves & 285 \\
\hline
\end{tabular}

Fonte: Adaptado de SGANZERLA (1983).

\footnotetext{
${ }^{1}$ A expressão "sistema biointegrado" costuma ser aplicada ao desenvolvimento sistemático e de forma integrada de uma ou mais atividades rurais, seja na criação de suínos, bovinos, caprinos, ovinos, seja de muares, entre outras, em uma mesma propriedade rural, de tal forma que uma atividade termine por complementar a outra, com aproveitamento das potencialidades de cada uma (ANGONESE et al., 2006).
} 
O principal componente do biogás é o gás metano, que é incolor e altamente combustível, e não produz fuligem. Em função da participação percentual do metano na composição do biogás, o poder calorífico deste pode variar de 5.000 a $7.000 \mathrm{kcal}$ por metro cúbico. Esse poder calorífico pode chegar a $12.000 \mathrm{kcal}$ por metro cúbico se eliminado todo o gás carbônico da mistura (DEGANUTTI et al., 2002).

A utilização do biogás para geração de eletricidade é uma atividade onde se podem obter os Certificados de Emissões Reduzidas, os chamados créditos de carbono. A simples queima do gás metano, mesmo produzindo dióxido de carbono, é válida, pois o metano possui um impacto de efeito estufa cerca de 21 vezes maior do que o dióxido de carbono (RANZI \& ANDRADE, 2004).

Este trabalho teve como objetivo identificar os custos e benefícios do processo de conversão de biogás em energia elétrica e analisar a viabilidade econômica do processo, utilizando a abordagem de estudo de caso, em uma agroindústria da região de São Manuel.

\section{MATERIAL E MÉTODOS}

Este estudo foi realizado numa agroindústria localizada no município de São Manuel, Estado de São Paulo, situada a uma latitude de 22 43'50” sul e longitude de 48 34 '14" oeste. O clima da região é do tipo $\mathrm{Cfa}$ (Método de Köeppen), clima temperado quente, mesotérmico e úmido, com temperatura média ambiente de $22^{\circ} \mathrm{C}$ (CUNHA \& MARTINS, 2009).

A propriedade desenvolve diversas atividades, como criação de aves poedeiras, cafeicultura, suinocultura com 2.300 suínos em fase de crescimento e terminação, e criação de ovinos e bovinos, em menor escala. A suinocultura, pelo fato de gerar grande quantidade de dejetos, com dificuldade de disposição no meio ambiente, foi selecionada para o processo de biodigestão anaeróbia.

O biodigestor analisado neste estudo tem o formato tubular e operação contínua, com calha de água em alvenaria e com uma manta plástica como gasômetro, representado na Figura 1.

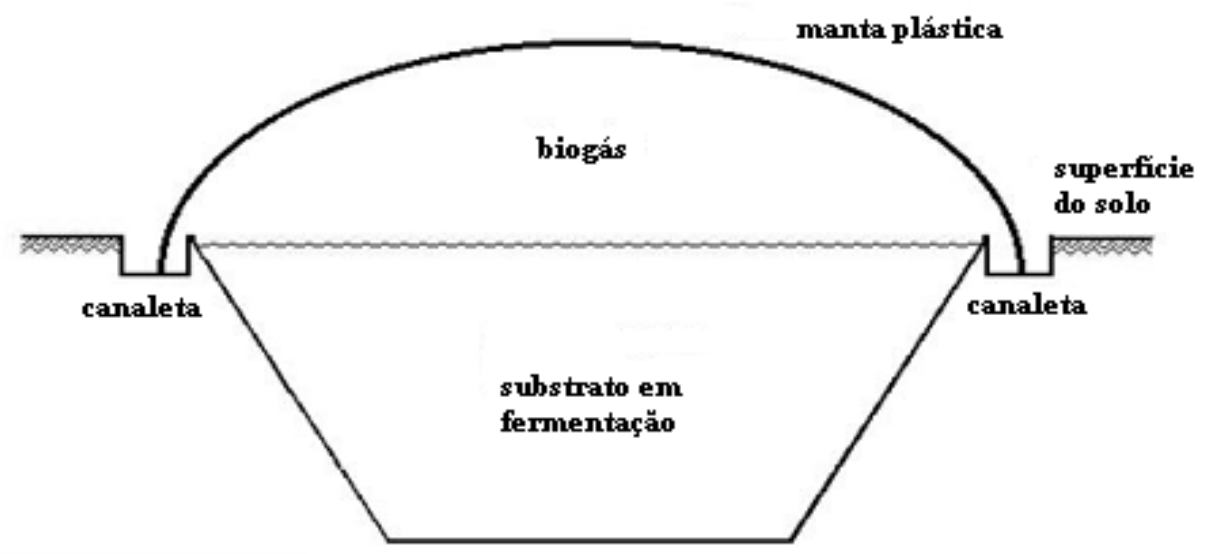

FIGURA 1. Seção transversal do biodigestor modelo tubular. Cross section of a tubular biodigester model.

Conforme os dados da Tabela 2, o biodigestor possui um volume útil de $496 \mathrm{~m}^{3}$. Os dejetos gerados pelos suínos são conduzidos para uma caixa de homogeneização de fluxo, caixa de entrada, e enviados diretamente para o biodigestor, com tempo de residência estimado em 35 dias. A quantidade de dejetos líquidos produzidos varia conforme o tipo de manejo, ou seja, dependendo da quantidade de água utilizada para a limpeza.

TAKITANE (2001) aponta que, para suínos em terminação com média de peso de $91 \mathrm{~kg}$, a produção de dejetos é de $6,1 \mathrm{~L} \mathrm{dia}^{-1}$ de dejetos líquidos. Dessa maneira, pode-se estimar que 2.300 suínos em terminação produzam aproximadamente $14,03 \mathrm{~m}^{3}$ de dejetos por dia. 
TABELA 2. Dimensões do biodigestor. Biodigester dimensions.

\begin{tabular}{|c|c|c|c|c|c|c|c|c|c|}
\hline & $\begin{array}{l}\text { Altura } \\
\text { (m) }\end{array}$ & $\mathrm{h} / 3$ & $\begin{array}{l}\text { Largura } \\
\text { Inferior } \\
(\mathrm{m})\end{array}$ & $\begin{array}{l}\text { Comprimento } \\
\text { Inferior } \\
(\mathrm{m})\end{array}$ & $\begin{array}{c}\text { Largura } \\
\text { Superior } \\
(\mathrm{m})\end{array}$ & $\begin{array}{l}\text { Comprimento } \\
\text { Superior } \\
(\mathrm{m})\end{array}$ & $\begin{array}{l}\text { Área } \\
\text { Inferior } \\
\left(\mathrm{m}^{2}\right)\end{array}$ & $\begin{array}{c}\text { Área } \\
\text { Superior } \\
\left(\mathrm{m}^{2}\right)\end{array}$ & $\begin{array}{c}\text { Volume } \\
\left(\mathrm{m}^{3}\right)\end{array}$ \\
\hline Volume de escavação & 2,8 & 0,9 & 7,0 & 22,0 & 10,0 & 25,0 & 154,0 & 258,0 & 571,0 \\
\hline Jolume útil & 2,5 & 0,8 & 7,0 & 22,0 & 10,0 & 25,0 & 154,0 & 246,0 & 496,0 \\
\hline
\end{tabular}

Fonte: Dados da pesquisa (2008).

O efluente do biodigestor é conduzido por uma caixa de saída e enviado para um reservatório onde o biofertilizante é bombeado, com o uso de uma motobomba, para irrigação de pastagens.

O biogás, ao ser produzido, é utilizado diretamente pelo conjunto motor-gerador que gera a energia elétrica utilizada no processo automatizado de seleção de ovos (Figura 2).

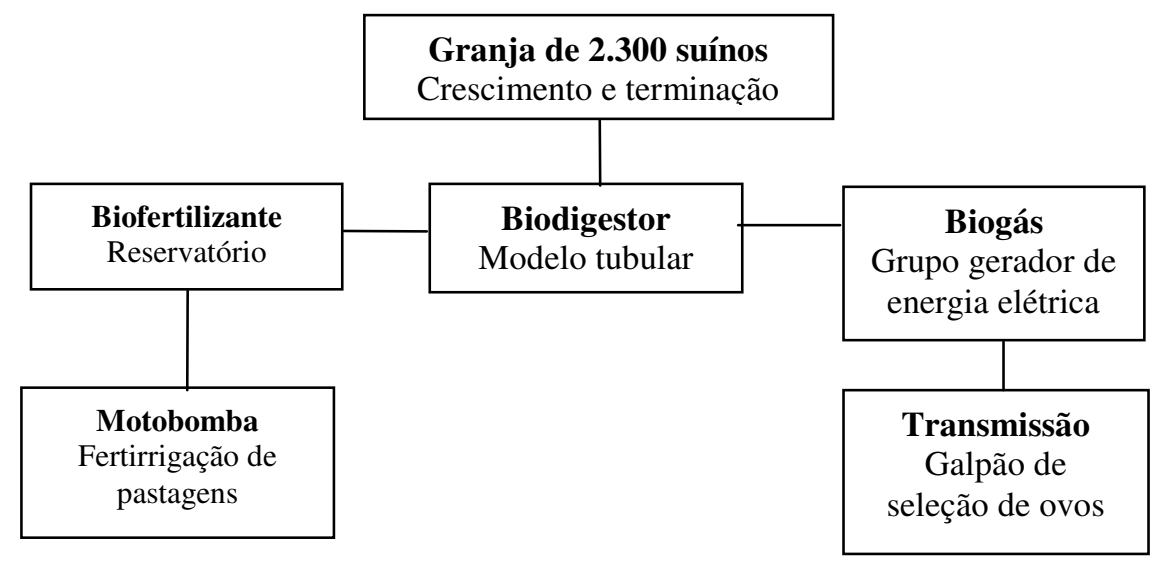

FIGURA 2. Fluxograma do sistema biointegrado. Flowchart of the biointegraded system.

Utilizou-se dos dados de SANTOS (2000) descritos na Tabela 3, para determinar que cada suíno em fase de terminação produz $0,799 \mathrm{~m}^{3}$ diários de biogás. Portanto, estima-se que, para 2.300 suínos em fase de terminação, a produção diária é de aproximadamente $1.837,7 \mathrm{~m}^{3}$ de biogás.

TABELA 3. Produção de biogás a partir de resíduos da suinocultura. Biogas production from swine waste.

\begin{tabular}{cccc}
\hline Espécie Pecuária & Unidade de Referência & $\begin{array}{c}\text { Produção Específica de } \\
\text { Biogás } \\
\left(\mathrm{m}^{3} \mathrm{~kg}^{-1} \mathrm{SV}^{2}\right)\end{array}$ & $\begin{array}{c}\text { Produção Diária } \\
\left(\mathrm{m}^{3} \text { animal }^{-1} \mathrm{dia}^{-1}\right)\end{array}$ \\
\hline \multirow{2}{*}{ Suínos $^{1}$} & $\begin{array}{c}\text { Porca reprodutora em } \\
\text { ciclo fechado }\end{array}$ & 0,45 & 0,866 \\
\cline { 2 - 4 } & $\begin{array}{c}\text { Porca reprodutora em } \\
\text { criação de leitões }\end{array}$ & 0,45 & 0,933 \\
\cline { 2 - 4 } & $\begin{array}{c}\text { Porco em exploração de } \\
\text { engorda }\end{array}$ & 0,45 & 0,799 \\
\hline
\end{tabular}

Fonte: SANTOS (2000). ${ }^{1}$ Chorume diluído com águas de lavagem. ${ }^{2}$ SV - sólidos voláteis.

Com uma disponibilidade constante de dejetos, a produção de biogás é diária, sendo interrompida apenas para a manutenção esporádica. A produção anual de biogás foi estimada por meio da eq.(1):

$$
\mathrm{P}_{\mathrm{AB}}=\mathrm{P}_{\mathrm{DB}} \mathrm{T}
$$


em que,

$\mathrm{P}_{\mathrm{AB}}$ - produção anual de biogás, $\mathrm{m}^{3}$ ano ${ }^{-1}$;

$\mathrm{P}_{\mathrm{DB}}$ - produção diária de biogás, $\mathrm{m}^{3}$ dia $^{-1}$, e

$\mathrm{T}$ - disponibilidade anual da planta, dias nno $^{-1}$.

O consumo específico de biogás pelo grupo gerador foi estimado em $22 \mathrm{~m}^{3} \mathrm{~h}^{-1}$, relação entre o volume de biogás consumido pelo grupo gerador e a energia elétrica gerada pelo mesmo, fornecida pelo fabricante do grupo gerador. Dessa maneira, a estimativa do consumo anual de biogás utilizado pelo conjunto motor-gerador foi feita por meio da eq.(2):

$$
\mathrm{C}_{\mathrm{AB}}=\mathrm{C}_{\mathrm{EB}} \mathrm{T}
$$

em que,

$\mathrm{C}_{\mathrm{AB}}$ - consumo anual de biogás, $\mathrm{m}^{3}$ ano $^{-1}$;

$\mathrm{C}_{\mathrm{EB}}$ - consumo específico de biogás pelo conjunto motor-gerador, $\mathrm{m}^{3} \mathrm{~h}^{-1}$, e

$\mathrm{T}$ - disponibilidade anual da planta, $\mathrm{h}$ ano ${ }^{1}$.

Com a utilização do analisador de rede denominado Circuitor AR5-L ${ }^{\circledR}$ que é composto por um conjunto com cabos flexíveis de até $6.000 \mathrm{~A}$, com registros de intervalos de 10 minutos em cada medição, os dados foram monitorados entre os dias 21 e 27 de fevereiro de 2008. Por meio deste conjunto de observações de medições, foram coletados os dados da energia elétrica consumida pela agroindústria disponibilizada pelo grupo gerador.

O gerador de eletricidade é trifásico, 220/380 VCA (Volts em Corrente Alternada), $3.600 \mathrm{rpm}, 60 \mathrm{~Hz}$, com capacidade nominal de geração de $50 \mathrm{kVA}$. Conforme a norma NBR 5410 da Associação Brasileira de Normas Técnicas (ABNT, 2004), para cálculos de geração de energia elétrica em baixa tensão, considerando-se um fator de potência de $0,8(\cos \varnothing)$, apresenta uma geração máxima de potência de $40 \mathrm{~kW}$. Também possui controle de rotação eletrônico do tipo isócrono; com sensor eletromagnético, e proteção contra sub e sobrevelocidade. O gerador foi acoplado a um motor de $2000 \mathrm{CC}$, de quatro cilindros, adaptado para uso com biogás.

Os benefícios gerados com a produção de energia elétrica gerada no grupo gerador foram interpretados como a renda que se deixa de transferir para a concessionária de energia elétrica, quando se produz a energia elétrica internamente. A propriedade está classificada com tarifa horo-sazonal verde, caracterizada pela aplicação de tarifas diferenciadas em horários de ponta ou fora de ponta e, também, nos períodos seco (maio a novembro) ou úmido (dezembro a abril), para o consumo de energia (Tabela 4).

TABELA 4. Preço do kWh estabelecido pela concessionária de energia elétrica. Price per kWh set by the electric utility.

\begin{tabular}{lcc}
\hline & Período Seco & Período Úmido \\
\cline { 2 - 3 } & $\mathrm{R} \$ \mathrm{kWh}^{-1}$ & ${\mathrm{R} \$ \mathrm{kWh}^{-1}}^{-1}$ \\
\hline Tarifa no horário de ponta (das 18 as $21 \mathrm{~h})$ & 0,694 & 0,671 \\
\hline Tarifa no horário fora de ponta (demais horas do dia) & 0,165 & 0,151 \\
\hline
\end{tabular}

Fonte: COMPANHIA PAULISTA DE FORÇA E LUZ (2008).

Da energia gerada pelo grupo gerador, considerou-se apenas a energia que foi consumida pela propriedade. Dessa maneira, o benefício obtido, por meio da equação 3, foi interpretado como o consumo de energia elétrica em função do tempo de operação da planta e da tarifa de energia elétrica paga pelo proprietário.

$$
\mathrm{B}_{\mathrm{GEE}}=\left(\mathrm{EE}_{\mathrm{C}} \mathrm{T}\right) \mathrm{T}_{\mathrm{EE}}
$$


em que,

$\mathrm{B}_{\mathrm{GEE}}$ - benefício com a geração de energia elétrica, $\mathrm{R} \$ \mathrm{ano}^{-1}$;

$\mathrm{EF}_{\mathrm{C}}$ - energia elétrica consumida, $\mathrm{kWh}$;

$\mathrm{T}$ - tempo de operação, $\mathrm{k}$ ano-1, $\mathrm{e}$

$\mathrm{T}_{\mathrm{EE}}$ - tarifa de energia elétrica, $\mathrm{R} \$ \mathrm{kWh}^{-1}$.

O investimento inicial foi classificado como o gasto necessário para a implantação das instalações e aquisição dos materiais e equipamentos. Os custos unitários foram determinados por meio de cotações realizadas em fevereiro de 2008 na região e de comprovantes de pagamento fornecidos pela propriedade. A estimativa do valor do investimento inicial foi feito por meio da eq.(4):

$$
\mathrm{II}=\mathrm{CM}+\mathrm{MO}
$$

em que,

II - investimento inicial, $\mathrm{R} \$$;

$\mathrm{CM}$ - custos com materiais e equipamentos, $\mathrm{R} \$$, e

$\mathrm{MO}$ - custos com mão de obra, $\mathrm{R} \$$.

Os custos anuais do sistema podem ser determinados considerando-se os custos fixos referentes à depreciação e aos juros sobre o capital imobilizado; e os custos variáveis referem-se à manutenção e à operação. $\mathrm{O}$ método de depreciação utilizado foi o da depreciação linear, descrito por NOGUEIRA (2001), conforme mostra a eq.(5):

$$
\mathrm{D}=\frac{\mathrm{C}_{\mathrm{i}}-\mathrm{C}_{\mathrm{f}}}{\mathrm{V}_{\mathrm{u}}}
$$

em que,

$\mathrm{D}$ - depreciação anual, $\mathrm{R} \$$ ano $^{-1}$

$\mathrm{C}^{\mathrm{i}}$ - custos de materiais depreciáveis, $\mathrm{R} \$$;

$\mathrm{C}_{\mathrm{f}}$ - valor final do ativo, $\mathrm{R} \$$, e

$\mathrm{V}_{\mathrm{u}}$ - vida útil, anos.

Os juros sobre o capital investido, também interpretado como o custo de oportunidade do capital, foram determinados em relação ao capital médio durante a vida útil dos bens, a uma taxa de juros de 5,64\% ao ano, que é o rendimento médio de cadernetas de poupança, pelo fato de o montante de recursos investidos não ser elevado. Segundo o método descrito por NOGUEIRA (2001), o custo de oportunidade do capital pode ser obtido utilizando-se da eq.(6):

$$
\mathrm{V}_{\mathrm{k}}=\frac{\mathrm{V}_{\mathrm{i}}+\mathrm{V}_{\mathrm{f}}}{2} \mathrm{r}
$$

em que,

$\mathrm{V}_{\mathrm{k}}$ - custo de oportunidade do capital, $\mathrm{R} \$ \mathrm{ano}^{-1}$;

$\mathrm{V}_{\mathrm{i}}$ - valor total do investimento, $\mathrm{R} \$$;

$\mathrm{V}_{\mathrm{f}}$ - valor final do ativo, $\mathrm{R} \$$, e

$\mathrm{r}$ - taxa de juros anuais, $\%$ ano $^{-1}$.

Os custos de manutenção foram computados como os gastos com a manutenção do grupo gerador e os gastos referentes à mão de obra para operar o sistema. Para estimar a manutenção do grupo gerador, foi considerado o intervalo de manutenção dos componentes como: troca de óleo e lubrificação, conforme o manual do equipamento fornecido pelo fabricante, em função do tempo de operação grupo gerador. Os custos foram baseados nos valores cobrados pela assistência técnica desses serviços na região, considerando-se os materiais utilizados, as taxas e os impostos. Assim, o gasto anual com a manutenção do grupo gerador pode ser obtido utilizando-se da eq.(7). 


$$
\mathrm{G}_{\mathrm{MGG}}=\left(\frac{\mathrm{T}}{\mathrm{I}_{\mathrm{M}}}\right) \mathrm{A}_{\mathrm{T}}
$$

em que,

$\mathrm{G}_{\mathrm{MGG}}$ - gastos com a manutenção do grupo gerador, $\mathrm{R} \$$ ano ${ }^{1}$;

$\mathrm{T}$ - tempo de operação, h ano ${ }^{1}$;

$\mathrm{I}_{\mathrm{M}}$ - intervalo de manutenção dos componentes, $\mathrm{h} \mathrm{unidade}^{1}$, e

$\mathrm{A}_{\mathrm{T}}$ - assistência técnica, $\mathrm{R} \$$ unidade $^{1}$.

A operação do grupo gerador é diária e exige a presença de uma pessoa responsável pela ignição do motor, limpeza e zelo das instalações. O custo da mão de obra para manter o biodigestor em operação é muito baixo devido à simplicidade do sistema. Faz-se necessária apenas uma limpeza esporádica para a remoção do lodo precipitado no biodigestor e da crosta que se forma na superfície. Assim, a estimativa dos gastos com mão de obra necessária para a manutenção do sistema foi obtida por meio da eq.(8):

$$
\mathrm{G}_{\mathrm{MO}}=\mathrm{T} \mathrm{G}_{\mathrm{S}}
$$

em que,

$\mathrm{G}_{\mathrm{MO}}$ - gastos com mão de obra para operação do sistema, $\mathrm{R} \$$ ano $^{-1}$;

$\mathrm{T}$ - tempo de operação, $\mathrm{h}$ ano ${ }^{-1}$, e

$\mathrm{G}_{\mathrm{S}}$ - gastos com salário, $\mathrm{R} \$ \mathrm{~h}^{-1}$.

Estabelecidos os custos e benefícios do sistema, foram determinados o fluxo de caixa do projeto e a análise de viabilidade econômica por meio dos seguintes indicadores: Valor Presente Líquido (VPL), Taxa Interna de Retorno (TIR), Relação Benefício-Custo (RBC) e Período de Recuperação do Capital (Payback Time). Também foi realizada a análise de sensibilidade do projeto com a simulação do consumo médio de energia elétrica. Dessa maneira, foi analisado o efeito da variação do consumo de energia elétrica no resultado econômico.

Conforme NOGUEIRA (2001), o valor presente líquido (VPL) é um indicador que permite avaliar a viabilidade econômica do projeto durante seu período de vida útil. O VPL é definido pelo valor atual dos benefícios menos o valor atual dos custos ou desembolsos, que foi calculado utilizando-se da eq.(9):

$$
\mathrm{VPL}=\sum_{\mathrm{i}=0}^{\mathrm{n}} \frac{\mathrm{B}_{\mathrm{i}}-\mathrm{C}_{\mathrm{i}}}{(1+\mathrm{r})^{\mathrm{i}}}
$$

em que,

$\mathrm{Bi}$ - benefício do projeto, em unidades monetárias, no ano i;

$\mathrm{Ci}$ - custo do projeto, em unidades monetárias, no ano i;

$\mathrm{r}$ - taxa de desconto, \%;

i - contador de tempo, em anos, e

$\mathrm{n}$ - período de vida útil do investimento, em anos.

O VPL representa, em valores monetários presentes, a diferença entre os recebimentos e os pagamentos de todo o projeto. Se o VPL for positivo, significa que foi recuperado o investimento inicial aplicado à taxa mínima de atratividade (TMA), sendo neste trabalho adotada uma taxa mínima de atratividade de 5,64\% a.a.

O método da taxa interna de retorno (TIR) requer o cálculo da taxa que zera o valor presente líquido (VPL). A taxa interna de retorno (TIR) foi determinada pela eq.(10):

$$
\sum_{i=0}^{n} \frac{B_{i}-C_{i}}{(1+r)^{i}}=0
$$


em que,

$\mathrm{B}_{\mathrm{i}}$ - benefício do projeto, em unidades monetárias, no ano i;

$\mathrm{C}_{\mathrm{i}}$ - custo do projeto, em unidades monetárias, no ano $\mathrm{i}$;

$\mathrm{r}$ - taxa interna de retorno, \%;

i - contador de tempo, em anos, e

$\mathrm{n}$ - período de vida útil do investimento, em anos.

Os projetos de investimentos que apresentam TIR maior que a taxa de mínima de atratividade são considerados viáveis (CASAROTTO FILHO \& KOPITTKE, 2007).

A relação benefício-custo (RBC) é um indicador que representa o retorno por unidade de capital ao longo do período do projeto, sendo obtido pela razão entre o fluxo de benefícios e os custos descontados. NOGUEIRA (2001) aponta que, para um projeto ser viável economicamente, esta relação, em princípio, deverá ser maior que 1, ou seja, $\mathrm{RBC}>1$. Esse indicador representa a relação entre o valor atual dos benefícios esperados e o valor atual dos custos esperados. A relação benefício-custo pode ser obtida por meio da eq.(11):

$$
R B C=\sum_{i=0}^{n} \frac{B_{i}(1+r)^{-i}}{C_{i}(1+r)^{-i}}
$$

em que,

$\mathrm{B}_{\mathrm{i}}$ - benefício do projeto, em unidades monetárias, no ano i;

$\mathrm{C}_{\mathrm{i}}$ - custo do projeto, em unidades monetárias, no ano $\mathrm{i}$;

$\mathrm{r}$ - taxa de desconto, \%;

i - contador de tempo, em anos, e

$\mathrm{n}$ - período de vida útil do investimento, em anos.

O período de recuperação do capital, também conhecido como Payback Time ou Payback Simples (PBS), consiste essencialmente em determinar o tempo necessário para que o somatório do fluxo de caixa seja igual ao investimento inicial. Já o Payback descontado ou Payback econômico (PBE), considera que o somatório do fluxo de caixa descontado a uma taxa mínima de atratividade (TMA) seja, no mínimo, igual ao investimento inicial (CASAROTTO FILHO \& KOPITTKE, 2007).

NOGUEIRA \& ZÜRN (2005), em estudo sobre o desenvolvimento de um novo modelo para dimensionamento de sistemas integrados de recursos energéticos renováveis, aplicados em ambientes rurais, com a utilização de ferramentas de simulação e otimização, concluíram que o dimensionamento dos sistemas energéticos e os custos são fundamentais para a tomada de decisões em projetos de energização rural, considerando critérios técnicos e econômicos.

\section{RESULTADOS E DISCUSSÃO}

A produção de biogás depende diretamente das condições de manutenção e operação do biodigestor e do resíduo. A produção de biogás foi de $670.760,5 \mathrm{~m}^{3} \mathrm{ano}^{-1}$. O biogás produzido foi utilizado diretamente no sistema de conversão de energia elétrica, que é utilizado por 10,5 horas dia ${ }^{-1}$, em média, com exceção de domingos e feriados. Assim, foi estimado um período de 26 dias por mês e 312 dias de operação por ano, que resultou em 3.276 horas de operação por ano. O consumo de biogás foi de $72.072 \mathrm{~m}^{3} \mathrm{ano}^{-1}$.

Este consumo representou aproximadamente 10,74\% do volume de biogás produzido pela planta. $O$ conjunto motor-gerador opera, em média, das 7 às $17 \mathrm{~h} 30$. Dessa maneira, foi considerada a tarifa cobrada no horário fora de ponta. 
Conforme os dados obtidos por meio das medições realizadas pelo analisador de rede (Figura 3), o consumo médio diário foi de $17,1 \mathrm{kWh}$. As medições foram realizadas para se obterem resultados que condizem com a rotina normal da propriedade durante o período de coleta de dados.

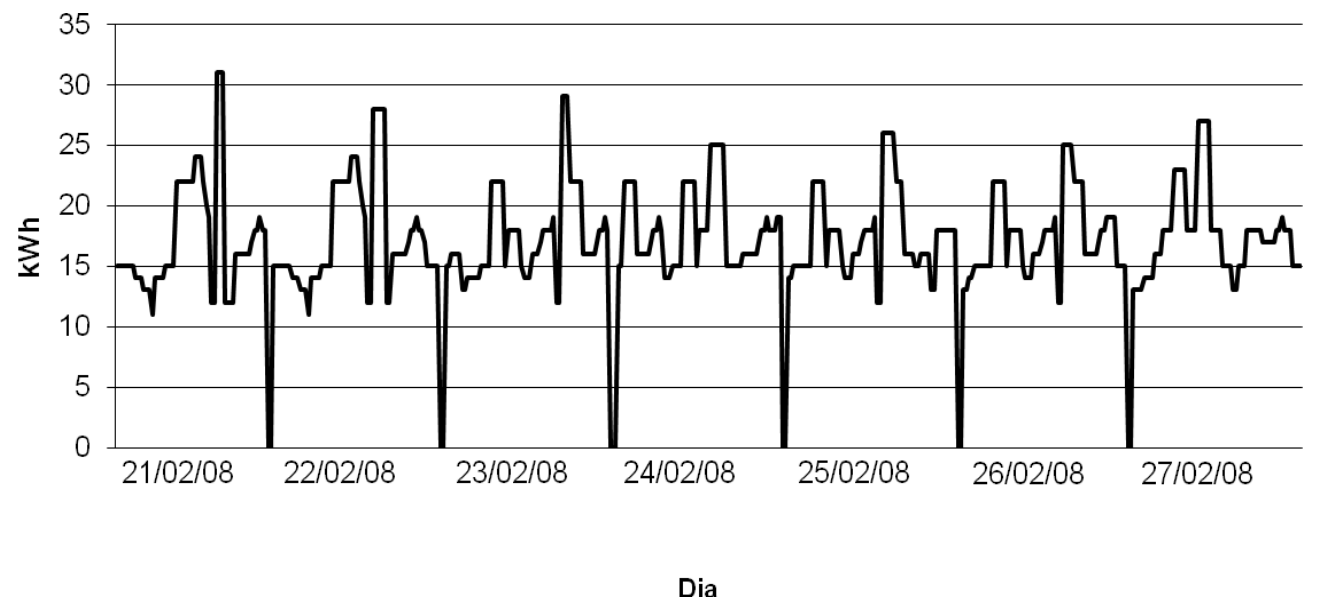

FIGURA 3. Medições do consumo de energia elétrica. Measurements of energy consumption.

Foram consideradas as tarifas de energia tanto no período "seco" quanto no período "úmido" do ano, no horário fora de ponta. Assim, o benefício com a geração de energia elétrica foi ponderado considerando a tarifa de $\mathrm{R} \$ 0,165 \mathrm{kWh}^{-1}$, por um período de 7 meses (período seco) e $\mathrm{R} \$ 0,151 \mathrm{kWh}^{-1}$, por um período de 5 meses (período úmido), que resultou num benefício de $\mathrm{R} \$ 8.916,45$ ano $^{-1}$.

O gerador apresenta o parâmetro de tensão trifásica de $220 \mathrm{~V}$. A corrente máxima a ser solicitada pela carga instalada pode ser de 131,82 A. No entanto, apesar de o grupo gerador disponibilizar $40 \mathrm{~kW}$ de potência máxima, as medições indicam que o consumo médio está em 17,1 kWh, ou seja, 56,35 A. Portanto, utiliza apenas 43\% da potência disponível pelo gerador.

O investimento inicial (Tabela 5) e os custos anuais de operação foram determinados por meio de levantamento de dados junto à propriedade.

TABELA 5. Investimento inicial. Initial investment.

\begin{tabular}{lc}
\hline Aquisição do grupo gerador & $28.594,00$ \\
\hline Construção do biodigestor & $15.276,77$ \\
\hline Construção do abrigo do grupo gerador & 785,95 \\
\hline Instalações elétricas & $4.110,45$ \\
\hline Mão de obra para implantação & $2.770,00$ \\
\hline Total & $51.537,17$ \\
\hline
\end{tabular}

Fonte: Dados da pesquisa (2008).

Para a determinação dos custos anuais do sistema, foram considerados: custos de depreciação, juros sobre o capital fixo e custos de manutenção e operação, apresentados nas Tabelas 6; 7 e 8.

A operação do grupo gerador é diária e exige a presença de um funcionário que é responsável pela ignição e desligamento do motor, limpeza e zelo das instalações. Assim, o tempo de operação exigido foi estimado em $200 \mathrm{~h} \mathrm{ano}^{-1}$, e os gastos com salários, de $\mathrm{R} \$ 2,98 \mathrm{~h}^{-1}$. Assim, o custo da mão de obra necessária para a manutenção, tempo de operação exigido em função do salário, foi de $\mathrm{R} \$ 596,00 \mathrm{ano}^{-1}$. Os gastos totais com manutenção e operação do biodigestor e grupo gerador foram de $\mathrm{R} \$ 5.708,20 \mathrm{ano}^{-1}$. Esse custo representou aproximadamente 11,08\% do investimento inicial para a implantação do sistema. Os custos anuais de depreciação, juros sobre o capital investido e manutenção e operação do sistema totalizaram $\mathrm{R} \$ 11.465,37$, conforme dados da Tabela 9. 
TABELA 6. Custos de depreciação dos bens. Depreciation costs.

\begin{tabular}{lcccc}
\hline \multirow{2}{*}{ Custos de Depreciação } & Valor Inicial & Valor Final* $^{*}$ & Vida Útil & Depreciação \\
\cline { 2 - 5 } & $(\mathrm{R} \$)$ & $(\mathrm{R} \$)$ & $($ anos $)$ & $\left(\mathrm{R} \$\right.$ ano $\left.^{-1}\right)$ \\
\hline Biodigestor Alvenaria e outros materiais & $8.340,35$ & - & 20 & 417,02 \\
\hline Abrigo do conjunto motor-gerador & 785,95 & - & 20 & 39,30 \\
\hline Manta plástica do biodigestor & $6.636,42$ & - & 10 & 663,64 \\
\hline Instalações elétricas & $4.110,45$ & - & 10 & 411,05 \\
\hline Grupo gerador & $28.594,00$ & - & 10 & $2.859,40$ \\
\hline Total & & & & $4.390,40$ \\
\hline *Não foi con
\end{tabular}

*Não foi considerado o valor final dos materiais e equipamentos.

TABELA 7. Juros sobre o capital investido. Interest on the invested capital.

\begin{tabular}{lcccc}
\hline \multirow{2}{*}{ Capital Investido } & Valor Inicial & Valor Final* $^{*}$ & Taxa de Juros & Juros \\
\cline { 2 - 5 } & $(\mathrm{R} \$)$ & $(\mathrm{R} \$)$ & $\left(\%\right.$ ano $\left.^{-1}\right)$ & $\left(\mathrm{R} \$\right.$ ano $\left.^{-1}\right)$ \\
\hline Biodigestor Alvenaria e outros materiais & $8.340,35$ & - & 5,64 & 235,20 \\
\hline Abrigo do conjunto motor-gerador & 785,95 & - & 5,64 & 22,16 \\
\hline Manta plástica do biodigestor & $6.636,42$ & - & 5,64 & 187,15 \\
\hline Instalações elétricas & $4.110,45$ & - & 5,64 & 115,91 \\
\hline Grupo gerador & $28.594,00$ & - & 5,64 & 806,35 \\
\hline Total & & & & $1.366,77$ \\
\hline
\end{tabular}

*Não foi considerado o valor final dos materiais e equipamentos.

TABELA 8. Manutenção preventiva do grupo gerador. Preventive maintenance of the generator.

\begin{tabular}{|c|c|c|c|}
\hline Componente & Intervalo (horas) & $\begin{array}{c}\text { Custo de Operação e } \\
\text { Manutenção (R\$) }\end{array}$ & $\begin{array}{c}\text { Custo Anual de Operação } \\
\text { e Manutenção (R\$) }\end{array}$ \\
\hline Óleo lubrificante & Troca de óleo a cada 100 horas & 80,00 & $2.620,80$ \\
\hline Filtro de óleo & Troca de filtro de óleo a cada 400 horas & 52,00 & 425,88 \\
\hline \multirow{2}{*}{$\begin{array}{l}\text { Sistema de } \\
\text { combustível }\end{array}$} & Limpeza dos filtros a cada 200 horas & 15,00 & 245,70 \\
\hline & $\begin{array}{l}\text { Limpeza da válvula de gás a cada } 2.000 \\
\text { horas }\end{array}$ & 15,00 & 24,57 \\
\hline \multirow{2}{*}{ Filtro de ar } & Limpeza a cada 1.000 horas & 15,00 & 49,14 \\
\hline & Troca do filtro de ar a cada 2.000 horas & 86,00 & 140,87 \\
\hline $\begin{array}{l}\text { Sistema de } \\
\text { refrigeração }\end{array}$ & $\begin{array}{l}\text { Troca do líquido refrigerante, da correia } \\
\text { dentada e do esticador da correia a cada } \\
1.000 \text { horas. }\end{array}$ & 220,00 & 720,72 \\
\hline \multirow[t]{2}{*}{ Alternador } & $\begin{array}{l}\text { Troca da correia e do jogo de velas a } \\
\text { cada } 1.000 \text { horas }\end{array}$ & 200,00 & 655,20 \\
\hline & Troca dos rolamentos a cada 2.000 horas & 100,00 & 163,80 \\
\hline $\begin{array}{l}\text { Rolamento do } \\
\text { gerador }\end{array}$ & Lubrificar a cada 1.000 horas & 20,00 & 65,52 \\
\hline Total & & & $5.112,20$ \\
\hline
\end{tabular}

TABELA 9. Custos totais para operação do sistema. Total costs for the system operation.

\begin{tabular}{lc}
\hline Itens de Custo & $\mathrm{R} \$ \mathrm{ano}^{-1}$ \\
\hline Depreciação & $4.390,40$ \\
\hline Juros & $1.366,77$ \\
\hline Manutenção preventiva do grupo gerador & $5.112,20$ \\
\hline Mão de obra para operação do sistema & 596,00 \\
\hline Total & $11.465,37$
\end{tabular}

Os benefícios totais foram estimados em $\mathrm{R} \$ 8.916,45 \mathrm{ano}^{-1}$, e os custos totais foram de $\mathrm{R} \$ 11.465,37 \mathrm{ano}^{-1}$. Isso indica que os benefícios com a utilização do biogás para a geração de energia elétrica são insuficientes para a cobertura dos custos anuais. O fluxo de caixa do projeto foi 
estimado considerando-se um período de 10 anos de vida útil porque corresponde com a vida útil do grupo gerador de energia elétrica, bem de maior valor econômico, e descontado a uma taxa de desconto de $5,64 \%$ ao ano.

Considerando-se um investimento inicial de $\mathrm{R} \$ 51.537,17$, benefícios anuais de $\mathrm{R} \$ 8.916,45$ e custos anuais de $\mathrm{R} \$ 10.098,60^{2}$, obteve-se um fluxo de caixa de $-\mathrm{R} \$ 1.182,15$ do primeiro ao décimo ano. Assim, os indicadores de viabilidade econômica apresentam resultados economicamente inviáveis, mostrando que não houve um dimensionamento técnico apropriado da demanda de energia frente à oferta de energia do grupo gerador.

Foram simulados cenários de consumo de energia elétrica, média diária, de 20;25;30; 35 e $40 \mathrm{kWh}$, para relacionar os níveis de consumo de energia com os indicadores de viabilidade econômica, que são apresentados na Tabela 10. Os dados apontam que o investimento é viável economicamente, mantendo-se inalterado o período de utilização da planta de $10,5 \mathrm{~h} \mathrm{dia}^{-1}$, se o consumo de energia for de $35 \mathrm{kWh}$, onde o VLP é de R $\$ 9.494,90$, a TIR é 9,34\%, o RBC é 1,18, o PBS é 7,32 anos e o PBE é 9,04 anos.

TABELA 10. Simulação do consumo médio de energia elétrica para utilização de $10,5 \mathrm{~h} \mathrm{dia}^{-1}$. Simulation of the average consumption of electricity using $10.5 \mathrm{~h} \mathrm{dia}^{-1}$.

\begin{tabular}{|c|c|c|c|c|c|c|c|c|}
\hline $\begin{array}{l}\text { Consumo } \\
\text { Médio } \\
\text { de Energia } \\
(\mathrm{kWh}) \\
\end{array}$ & $\begin{array}{l}\text { Tempo de } \\
\text { Operação } \\
\left(\text { h dia }^{-1}\right)\end{array}$ & $\begin{array}{l}\text { Benefício } \\
\left(\mathrm{R} \$ \text { ano }^{-1}\right)\end{array}$ & $\begin{array}{c}\text { Custo* } \\
\left(\mathrm{R} \$ \mathrm{ano}^{-1}\right)\end{array}$ & $\begin{array}{l}\text { VPL } \\
\text { (R\$) }\end{array}$ & $\begin{array}{l}\text { TIR } \\
(\%)\end{array}$ & $\begin{array}{c}\mathrm{RBC} \\
\text { (Índice) }\end{array}$ & $\begin{array}{c}\text { PBS } \\
\text { (Anos) }\end{array}$ & $\begin{array}{c}\text { PBE } \\
\text { (Anos) }\end{array}$ \\
\hline 20 & 10,5 & $10.428,60$ & $10.098,60$ & $(49.066,37)$ & - & 0,05 & - & - \\
\hline 25 & 10,5 & $13.035,75$ & $10.098,60$ & $(29.545,95)$ & $-9,10 \%$ & 0,43 & - & - \\
\hline 30 & 10,5 & $15.642,90$ & $10.098,60$ & $(10.025,52)$ & $1,35 \%$ & 0,81 & 10,30 & - \\
\hline 35 & 10,5 & $18.250,05$ & $10.098,60$ & $9.494,90$ & $9,34 \%$ & 1,18 & 7,32 & 9,04 \\
\hline 40 & 10,5 & $20.857,20$ & $10.098,60$ & $29.015,32$ & $16,24 \%$ & 1,56 & 5,79 & 6,75 \\
\hline
\end{tabular}

*Neste custo, não está incluído os juros sobre o capital.

Também foi simulada a utilização do grupo gerador de energia no horário de ponta, das 18 às 21 h, onde há elevação da tarifa de energia elétrica cobrada pela concessionária de energia elétrica, no valor de $\mathrm{R} \$ 0,694 \mathrm{kWh}^{-1}$, por 7 meses no período seco, e de $\mathrm{R} \$ 0,671 \mathrm{kWh}^{-1}$, por 5 meses no período úmido, conforme os dados da Tabela 11.

TABELA 11. Benefícios econômicos simulados, com a geração de energia elétrica no horário de ponta. Economic benefits simulated, with the generation of electricity at peak hours.

\begin{tabular}{ccc}
\hline $\begin{array}{c}\text { Consumo Médio de Energia } \\
(\mathrm{kWh})\end{array}$ & $\begin{array}{c}\text { Tempo de Operação do Gerador } \\
\text { no Horário de Ponta }\left(\mathrm{h} \mathrm{dia}^{-1}\right)\end{array}$ & $\begin{array}{c}\text { Benefício com Geração de Energia } \\
\left(\mathrm{R} \$ \text { ano }^{-1}\right)\end{array}$ \\
\hline 17,1 & 3 & $10.954,50$ \\
\hline 20 & 3 & $12.812,28$ \\
\hline 25 & 3 & $16.015,35$ \\
\hline 30 & 3 & $19.218,42$ \\
\hline 35 & 3 & $22.421,49$ \\
\hline 40 & 3 & $25.624,56$ \\
\hline
\end{tabular}

Também foram simulados os custos variáveis com a manutenção preventiva do grupo gerador para diferentes tempos de operação diária (Tabela 12).

\footnotetext{
${ }^{2}$ Neste fluxo de caixa, não foram incluídos os juros sobre o capital, no item custos, pois os fluxos de caixa já são descontados por uma taxa de desconto, considerada como o custo de oportunidade do capital (5,64\% a.a.). Embora a depreciação não seja uma saída de caixa, optou-se por incluí-la, pois muitos autores defendem que esta afeta os fluxos de caixa pelo impacto sobre os impostos pagos.
} 
TABELA 12. Simulação dos custos variáveis com a manutenção do grupo gerador. Simulation of variable costs for maintaining the generator.

\begin{tabular}{cc}
\hline $\begin{array}{c}\text { Tempo de Operação do Gerador } \\
\left(\mathrm{h} \mathrm{dia}^{-1}\right)\end{array}$ & $\begin{array}{c}\text { Custo com Manutenção Preventiva do Grupo Gerador } \\
\left(\mathrm{R} \$ \text { ano }^{-1}\right)\end{array}$ \\
\hline 10,50 & $5.112,20$ \\
\hline 11,50 & $5.599,08$ \\
\hline 12,50 & $6.085,95$ \\
\hline 13,50 & $6.572,83$ \\
\hline
\end{tabular}

Os dados da Tabela 13 mostram que, com o consumo de 17,1 kWh, considerando um tempo de utilização de $10,5 \mathrm{~h} \mathrm{dia}^{-1}$ no horário fora de ponta e $3 \mathrm{~h} \mathrm{dia}^{-1}$ adicionais no horário de ponta, o investimento torna-se viável. Os dados também indicam que, quanto mais o consumo de energia elétrica se aproxima da capacidade máxima de geração de energia do grupo gerador de $40 \mathrm{kWh}$, menor será o tempo de retorno sobre o investimento realizado.

TABELA 13. Simulação do consumo médio de energia elétrica para utilização de $13,5 \mathrm{~h} \mathrm{dia}^{-1}$. Simulation of the average consumption of electricity using $13.5 \mathrm{~h} \mathrm{dia}^{-1}$.

\begin{tabular}{|c|c|c|c|c|c|c|c|c|}
\hline $\begin{array}{l}\text { Consumo } \\
\text { de Energia } \\
(\mathrm{kWh})\end{array}$ & $\begin{array}{c}\text { Tempo de } \\
\text { Operação } \\
\left(\mathrm{h} \mathrm{dia}^{-1}\right)\end{array}$ & $\begin{array}{l}\text { Benefício } \\
\left(\mathrm{R} \$ \text { ano }^{-1}\right)\end{array}$ & $\begin{array}{c}\text { Custo } \\
\left(\mathrm{R} \$ \text { ano }^{-1}\right)\end{array}$ & $\begin{array}{l}\text { VPL } \\
\text { (R\$) }\end{array}$ & $\begin{array}{l}\text { TIR } \\
(\%)\end{array}$ & $\begin{array}{c}\mathrm{RBC} \\
\text { (índice) }\end{array}$ & $\begin{array}{l}\text { PBS } \\
\text { (anos) }\end{array}$ & $\begin{array}{c}\text { PBE } \\
\text { (anos) }\end{array}$ \\
\hline 17,1 & 13,5 & $19.870,95$ & $11.559,23$ & $10.694,90$ & $9,79 \%$ & 1,21 & 7,20 & 8,85 \\
\hline 20 & 13,5 & $23.240,88$ & $11.559,23$ & $35.926,44$ & $18,52 \%$ & 1,70 & 5,41 & 6,22 \\
\hline 25 & 13,5 & $29.051,10$ & $11.559,23$ & $79.429,10$ & $31,79 \%$ & 2,54 & 3,95 & 4,32 \\
\hline 30 & 13,5 & $34.861,32$ & $11.559,23$ & $122.931,76$ & $44,04 \%$ & 3,39 & 3,21 & 3,44 \\
\hline 35 & 13,5 & $40.671,54$ & $11.559,23$ & $166.434,42$ & $55,82 \%$ & 4,23 & 2,77 & 2,92 \\
\hline 40 & 13,5 & $46.481,76$ & $11.559,23$ & $209.937,08$ & $67,37 \%$ & 5,07 & 2,48 & 2,59 \\
\hline
\end{tabular}

SOUZA et al. (2004), em estudo numa propriedade rural típica contendo aviário, pocilga, fábrica de ração e residência, estimaram o consumo em $39 \mathrm{kWh}$, constatando que seriam necessárias 258 matrizes de suínos com capacidade de gerar, cada uma, $0,775 \mathrm{~m}^{3}$ de biogás por dia, para instalação de um grupo gerador com potência de $40 \mathrm{~kW}$. Os autores concluíram que, para uma tarifa de energia elétrica de $\mathrm{R} \$ 0,19 \mathrm{kWh}^{-1}$, o tempo de recuperação do investimento é de 5,4 anos. Também apontaram que o retorno do investimento depende da tarifa de energia paga pelo produtor e do período de utilização da planta.

COLDEBELLA (2006) destaca que o custo de $\mathrm{m}^{3}$ de biogás produzido na propriedade está diretamente relacionado com a capacidade de produção de biogás em função do investimento necessário. Assim, a utilização do sistema durante $10 \mathrm{~h} \mathrm{dia}^{-1}$ apresentou um custo de $\mathrm{R} \$ 0,063 \mathrm{~m}^{-3}$ de biogás, concluindo que, com uma tarifa de energia elétrica de $\mathrm{R} \$ 0,30 \mathrm{kWh}^{-1}$, o retorno do investimento é de 2,7 anos quando há utilização simultânea do motor-gerador de energia elétrica durante $10 \mathrm{~h} \mathrm{dia}^{-1}$ e da motobomba durante $12 \mathrm{~h} \mathrm{dia}^{-1}$ para a aplicação do biofertilizante em pastagens.

ESPERANCINI et al. (2007) analisaram a viabilidade de implantação de dois biodigestores em assentamentos rurais com uso de dejetos animais, um para o fornecimento de energia para os domicílios, e outro para as atividades produtivas. O período de recuperação do investimento foi de 2,5 anos e 11 meses, para a utilização de biogás nos domicílios e nas atividades de produção, respectivamente. Os autores também indicaram que esses estudos podem servir como base para o desenvolvimento de políticas públicas direcionadas ao aproveitamento de biomassa para a produção de energia a baixos custos. 
JUNGES et al. (2009) realizaram um estudo sobre a análise econômico-financeira da implantação de diferentes modelos de biodigestores em duas propriedades (A e B), no município de Toledo no Estado do Paraná. Os autores apontaram que a grande quantidade de dejetos viabiliza a implantação de biodigestores porque gera maior produção de biogás, maior economia de energia elétrica e créditos de carbono. Constataram também que os ganhos ambientais, por si só, não motivam pequenos suinocultores a implantar sistemas de biodigestores em suas propriedades; dessa maneira, atualmente, os Mecanismos de Desenvolvimento Limpo - MDLs, são limitados a poucos produtores.

\section{CONCLUSÕES}

Concluiu-se que são gerados excedentes de biogás e de energia elétrica, que não são aproveitados no sistema biointegrado. Assim, é necessário analisar as alternativas para a utilização deste excedente bem como sua viabilidade técnica e econômica. Este estudo demonstrou que o sistema de produção de biogás é potencialmente viável do ponto de vista econômico, mas depende diretamente do dimensionamento técnico da demanda de energia elétrica para as diversas atividades da propriedade frente à oferta de energia do grupo gerador.

\section{REFERÊNCIAS}

ANGONESE, A.; CAMPOS, A. T.; ZACARKIM, C. E. Eficiência energética de sistema de produção de suínos com tratamento dos resíduos em biodigestor. Revista Brasileira de Engenharia Agrícola e Ambiental, Campina Grande, v.10, n.3, p.745-750, jul./set. 2006.

ABNT. ASSOCIAÇÃO BRASILEIRA DE NORMAS TÉCNICAS. NBR 1054: instalações elétricas de baixa tensão. São Paulo. 2004. Disponível em: <http://www.pdf-searchengine.com/download-normas-nbr-pdf.html. Acesso em: 27 abr. 2009.

CASAROTTO FILHO, N.; KOPITTKE, B. H. Análise de investimentos: matemática financeira, engenharia econômica, tomada de decisão, estratégia empresarial. 10.ed. São Paulo: Atlas, 2007. $468 \mathrm{p}$.

COLDEBELLA, A. Viabilidade do uso do biogás da bovinocultura e suinocultura para geração de energia elétrica e irrigação em propriedades rurais. Dissertação. 2006. 73 f. (Mestrado em Engenharia Agrícola / Engenharia de Sistemas Agroindustriais) - Universidade Estadual do Oeste do Paraná, Cascavel, 2006.

CPFL. COMPANHIA PAULISTA DE FORÇA E LUZ. Taxas e tarifas. Campinas, 2008. Disponível em: <http://agencia.cpfl.com.br/portal-servicos/paulista/taxas_tarifas.asp>. Acesso em: 31 out. 2008.

CUNHA, A.R.; MARTINS, D. Classificação climática para os municípios de Botucatu e São Manuel - SP. Irriga. Botucatu, v.14, n.1, p.1-11, 2009.

DEGANUTTI, R.; PALHACI, M. do C.J.P.; ROSSI, M. Biodigestores rurais: modelo indiano, chinês e batelada. In: ENCONTRO DE ENERGIA NO MEIO RURAL, 4., 2002, Campinas. Anais eletrônicos. Disponível em:

$<$ http://www.proceedings.scielo.br/scielo.php?script=sci_arttext\&pid=MSC0000000022002000100 031\&lng=pt\&nrm=abn>. Acesso em: 16 jul. 2010.

ESPERANCINI, M.S.T.; COLEN, F.; BUENO, O.C.; PIMENTEL, A.E.B.; SIMON, E.J. Viabilidade técnica e econômica da substituição de fontes convencionais de energia por biogás em assentamento rural do Estado de São Paulo. Engenharia Agrícola, Jaboticabal, v.27, n.1, p.110-118, 2007.

GASPAR, R.M.B.L. Utilização de biodigestores em pequenas e médias propriedades rurais com ênfase na agregação de valor: um estudo de caso na região de Toledo - PR. 2003. 106 f. 
Dissertação (Mestrado em Planejamento e Estratégia Organizacional) - Universidade Federal de Santa Catarina, Florianópolis, 2003.

JUNGES, D. M.; KLEINSCHMITT, S.C.; SHIKIDA, P.F.A., SILVA, J.R da. Análise econômico-financeira da implantação do sistema de biodigestores no Município de Toledo (PR). Revista de Economia, Curitiba, v.35, n.1, p.7-30, jan-abr. 2009.

MIRANDA, H.A. Influência da recirculação de efluentes e do tempo de retenção no desempenho de biodigestores operados com estrume de suínos. 1991. 137 f. Dissertação (Mestrado em Energia na Agricultura) - Faculdade de Ciências Agronômicas, Universidade Estadual Paulista, Botucatu, 1991.

NOGUEIRA, C.E.C.; ZÜRN, H.H. Modelo de dimensionamento otimizado para sistemas energéticos renováveis em ambientes rurais. Engenharia Agrícola, Jaboticabal, v.25, n.2, p.341348, 2005.

NOGUEIRA, E. Análise de investimentos. In: BATALHA, M. O. Gestão agroindustrial. 2.ed. São Paulo: Atlas, 2001. v.1. 692 p.

PECORA, V. Implantação de uma unidade demonstrativa de geração de energia elétrica a partir do biogás de tratamento do es goto residencial da USP: estudo de caso. 2006. 152 f. Dissertação (Mestrado em Energia) - Universidade de São Paulo, São Paulo, 2006.

RANZI, T.J.D.; ANDRADE, M.A.N. Estudo de viabilidade de transformação de esterqueiras e bioesterqueiras para dejetos de suínos em biodigestores rurais visando o aproveitamento do biofertilizante e do biogás. In: ENCONTRO DE ENERGIA NO MEIO RURAL E GERAÇÃO DISTRIBUÍDA, 5., 2004, Campinas. Anais... Campinas: Universidade Estadual de Campinas, 2004. 1 CD-ROM.

SANTOS, P. Guia técnico de biogás. CCE - Centro para a Conservação de Energia. Guia Técnico de Biogás. AGEEN - Agência para a Energia, Amadora, Portugal, p.117, 2000.

SEIXAS, J.; FOLLE, S.; MACHETTI, D. Construção e funcionamento de biodigestores. Brasília: Embrapa-DID, Embrapa-CPAC, 1980. p. 60. (Circular Técnica, 4).

SGANZERLA, E. Biodigestores: uma solução. Porto Alegre: Agropecuária, 1983.

SOUZA, S.N.M.; PEREIRA, W.C.; NOGUEIRA, C.E.C.; PAVAN, A.A.; SORDI, A. Custo da eletricidade gerada em conjunto motor-gerador utilizando biogás da suinocultura. Acta Scientiarum Technology, Maringá, v.26, p.127-133, 2004.

TAKITANE, I.C. Produção de dejetos e caracterização de possibilidades de aproveitamento em sistemas de produção de suínos com alta tecnologia no Estado de São Paulo. 2001. 148 f. Tese (Doutorado em Energia na Agricultura) - Faculdade de Ciências Agronômicas, Universidade Estadual Paulista, Botucatu, 2001. 